\title{
Goa na literatura indo-portuguesa ${ }^{1}$
}

\author{
Everton V. Machado \\ Centro de Estudos Comparatistas, Universidade de Lisboa
}

\begin{abstract}
RESUMO: ESTE ESTUDO É UMA REFLEXÃO SOBRE AS COMPLEXIDADES DA SOCIEDADE DE GOA REVELADAS EM SUA LITERATURA. POR TRÁS DE UMA SUPOSTA “COMUNHÃO DE MOSTEIROS E PAGODES", DIFERENÇAS RELIGIOSAS, CULTURAIS E SOCIOECONÔMICAS APONTAM PARA A NATUREZA IRRECONCILIÁVEL DE DOIS MEIOS HUMANOS QUE PARTILHAM MUITOS TRAÇOS DE SUA IDENTIDADE. OS AUTORES TRATADOS AQUI SÃO NATIVOS GOESES CRIADOS EM MEIO CATÓLICO E PORTUGUÊS.
\end{abstract}

ABSTRACT: THIS STUDY IS A REFLECTION ON THE COMPLEXITIES OF THE INDOPORTUGUESE CULTURE OF GOA AS REVEALED IN ITS LITERATURE. BEHIND THE SUPPOSED "COMMUNION OF MONASTERIES AND PAGODAS", RELIGIOUS AND SOCIOECONOMIC DIFFERENCES FEED AN IDENTIFIABLE BUT THUS FAR IRRECONCILABLE "CONFUSION" OF PERSONAL IDENTITY AND BEING. THE AUTHORS TREATED HEREIN ARE GOAN NATIVES RAISED IN A CATHOLIC AND PORTUGUESE-LIKE ENVIRONMENT.

PALAVRAS-CHAVE: LITERATURA INDO-PORTUGUESA, GOA, IDENTIDADE KEYWORDS: INDO-PORTUGUESE LITERATURE, GOA, IDENTITY

1. O presente artigo é uma versão em português (ligeiramente modificada e ampliada) da comunicação "Indo-Portuguese Literature and the Goa of Its Writers", apresentada em 28 de setembro de 2010 no colóquio internacional Portuguese and Luso-Asian Legacies in Southeast Asia 1511-2011, organizado em Cingapura e Malaca pelo Institute for Southeast Asian Studies, que detém os direitos de publicação em língua inglesa. 
ão há melhor introdução à Goa dos escritores indo-portugueses que um excerto do romance O último olhar de Manú Miranda, de Orlando da Costa (19292006), publicado pela Âncora em 2000. Poder-se-ia dizer que essa obra é um bildungsroman, o "romance de formação" do brâmane católico Manuel João da Piedade Miranda, vindo ao mundo algumas décadas antes do fim do período colonial português com duas sinas possíveis: tomar o caminho da metrópole à semelhança dos desiludidos com o seu torrão natal ou tornar-se batcar (proprietário de terras) a exemplo dos antepassados. O tal romance, no dizer do próprio Orlando da Costa, ${ }^{2}$ acompanha as vivências de Goa de seu autor, nascido em Moçambique e falecido em Portugal, mas cuja infância e adolescência foram profundamente goesas. No livro, a mãe de Manú dera-o à luz no mesmo momento em que também nascia aquele que ficou a ser em criança o seu melhor amigo, um menino hindu chamado Xricanta. As duas pequenas criaturas estavam "destinadas a serem gêmeas" (COSTA, 2000, p. 52), pois até as transformações corporais próprias à adolescência aconteciam para ambos "no mesmo dia e à mesma hora" (COSTA, 2000, p. 98). Uma só coisa os separava irremediavelmente: a religião, com a sua carga de preceitos e costumes.

Este pequeno estudo é uma reflexão sobre as complexidades da sociedade de Goa reveladas nas obras de autores do meio católico de língua portuguesa como - além de Orlando da Costa - Francisco Luís Gomes, Francisco João da Costa e Vimala Devi, e se pretende não mais que uma introdução geral ao tema, com indicação de pistas a serem exploradas no futuro. Por trás de uma suposta "comunhão de mosteiros e pagodes", diferenças religiosas, culturais e socioeconômicas apontam para a natureza irreconciliável de dois meios humanos que partilham muitos traços de sua identidade, sob a pátina da chamada singularidade ou especificidade goesa.

\section{$\mathrm{O}$ signo duma rotura}

Seria o caso de se perguntar se não fora intenção de Orlando da Costa fazer daquele modo em $O$ último olhar de Manú Miranda um clin d'cil ao célebre romance Midnight's children (1981) do também indiano (porém de família mu-

2. Na dedicatória que apôs ao exemplar que me ofereceu na Lousã em 01/11/2003. 
çulmana e escritor de língua inglesa) Salman Rushdie. Manú e Xricanta não foram trocados na maternidade como Saleem Sinai e Shiva, nem se haviam tornado inimigos jurados como estes dois últimos, mas se no livro do autor indo-britânico está em jogo a divergência sociorreligiosa que deu origem à partição da Índia e do Paquistão em 1947 e a qual encarnam as suas duas personagens, no livro do indo-português a natureza da barreira entre Manú e Xricanta, de mesma monta, não é menos relevante. Muito pelo contrário: é a consciência dela, desde muito cedo, que induzirá o protagonista às suas muitas dúvidas existenciais. A propósito disso, o narrador de Orlando da Costa não deixa de sublinhar a um dado momento que "não era costume darem-se entre si, cristãos e hindus, ao ponto de se conhecerem no interior das suas casas ou na intimidade das suas famílias” (COSTA, 2000, p. 58). Manú e Xricanta podiam até falar entre eles o concani, a língua natural de Goa (concão), mas ao retornar para casa o primeiro iria alterná-la com o português e o segundo com o marata, língua do Maharahstra, largamente difundida em Goa e utilizada especialmente pelos hindus com formação religiosa.

Já o excerto a que me referi logo de início traduz muito bem aquilo que Eufemiano de Jesus Miranda designa como "o signo duma rotura” (MIRANDA, 1995, p. 247) presente nos escritores indo-portugueses, rotura que se explica, naturalmente, pela delicada relação dos goeses formados em ambiente cristão e europeu - de onde provém a literatura aqui abordada - com o universo ancestral hindu. Eis o excerto, que, sem faltar à lógica própria ao esquema actancial da narrativa, suspeito resume o bildungsroman de todo goês católico:

A verdade, [...] é que, para além do mundo que [Manú Miranda] habitava, comum a todos, agora, o mundo que o habitava, oculto e sussurrante como uma nascente de águas subterrâneas, alargava-se a outras questões mais adequadas às crescentes marés emocionais e mentais da sua personalidade. Uma personalidade em formação, em busca de algum sentido para as suas raízes familiares e sociais, um emaranhado de folhas verdes e folhas secas presas ao mesmo ramo de uma mesma árvore há muito esquecida, órfã numa selva perdida da vista humana, no sopé da cordilheira do Gates desde os tempos mais antigos em que o deus Brahma terá criado o mundo e o tempo já recuado em que Parsurama 
lançou o dardo lendário da fertilidade nas terras de $\mathrm{Goa}^{3}$, mais tarde cobiçadas e invadidas por sucessivos conquistadores. Os Gates! Seria aí que ficava a fronteira entre Krishna e Cristo? Perdia-se na busca do seu passado genuíno e hesitante perante o futuro, sentia-se desprotegido e só, porventura culpado da intolerância da fé e da sua religião, que outrora pusera em fuga irmãos de sangue e de língua, carregando consigo ídolos sagrados, as próprias divindades, e as pedras com que mais tarde o brio dos resistentes e o orgulho dos perseguidos novamente reergueram a sul os seus templos em clareiras protegidas pela ramagem de mangueiras e no sossego suspenso dos altíssimos troncos das arequeiras. Que pensaria o seu amigo Xricanta, quase irmão nascido no mesmo dia e à mesma hora, no sábio recolhimento do seu eremitério? (COSTA, 2000, p. 104-105)

Esse excerto do romance $O$ último olhar de Manú Miranda revela uma temática que atravessa, de um modo geral, as obras mais relevantes da literatura goesa de língua portuguesa, oferecendo-nos uma representação de Goa segundo os olhos de homens e mulheres naturais educados em meio católico e aportuguesado. A divisão societal entre católicos e hindus e a comum origem ancestral, traçados dessa maneira nas obras goesas de língua portuguesa, dão ao leitor demasiado pragmático uma confusa e por vezes bastante incômoda sensação de inabarcabilidade do real diante da existência de dois universos ao mesmo tempo tão próximos e tão distantes na Goa outrora colonizada pelos portugueses. $^{4}$

A separação factual desses mundos é até representada, por assim dizer, materialmente, no livro de contos Monção (1963) de Vimala Devi (1936), em que as narrativas sobre ambos, escritas separadamente, quase que se alternam umas com as outras na organização dos textos, o que não impede personagens hindus e católicos de co-habitarem uma mesma história. Note-se que a autora mesmo da recolha encarna tal dilaceramento, pois Vimala Devi (nome hindu que significa algo como "deusa da pureza") ${ }^{5}$ é um pseudônimo adotado por

3. Trata-se de uma alusão ao mito da criação de Goa. O poeta Adeodato Barreto também o havia explorado, num canto nacionalista. Cf. o poema "Apoteose" (BARRETO, 2000, p. 267-274).

4. O mundo muçulmano de Goa merece muito pouca atenção, as suas personagens sendo relegadas a papéis secundários.

5. Do sânscrito Vimalä ("puro", "imaculado", "transparente"); devī ("deusa”, "rainha”). Cf. Sanskrit Heritage Dictionary. Disponível em: < http://sanskrit.inria.fr/sanskrit.html>. Acesso em 19 ago. 2010. 
Teresa da Piedade de Baptista Almeida, católica de formação cultural portuguesa. Vale salientar a respeito desse ponto que, como nenhum outro escritor goês católico de língua portuguesa, Vimala Devi é capaz de retratar com propriedade a Goa hindu, o próprio Orlando da Costa tendo afirmado o quão "curioso" é vê-la, "uma cristã de família e educada dentro dos moldes de comportamento social do goês europeizado, [conseguir] recriar personagens tanto de formação católica como da comunidade hindu, movendo-se num mundo real" (COSTA, 2005, p. 127). Também poeta, chega ela a observar, num poema intitulado "Goa", da obra Súria (1962), que no seu pensamento Goa será sempre "comunhão de mosteiros e pagodes" e que como poeta, por sentir "um apelo/dolorido e ancestral", a tarefa a que se propõe é a de ser "a voz da consciência:/a voz de dois mundos!" (DEVI, 1962, p. 27 e 28).

A consciência desse dilaceramento é sem dúvida muito maior nos escritores do período pós-colonial (como os próprios Orlando e Vimala), iniciado em 1961 com a partida dos portugueses de Goa, ainda que na chamada vaga "nativista" (que vai dos fins do século XIX às primeiras décadas do século seguinte) o sentimento de rotura já se tivesse exacerbado e que um poeta como Adeodato Barreto (1905-1937) pareça ter resolvido - ainda na década de 1930 - para si a questão, com os poemas de O livro da vida - Cânticos indianos (publicado postumamente em 1940), em que Goa surge iluminada pela tradição poética e filosófica hindu. De toda forma, a referida consciência, bem como as estratégias para resolver, contornar ou esvaziar o problema funcionam como pano de fundo a diversos temas ou motivos que compõem a imagem de Goa proposta pelos autores goeses de língua portuguesa. Daí a representação de uma Goa multifacetada, para além de histórica e etnograficamente delimitada.

Dentre esses temas está, et pour cause, o sistema indiano de castas, mantido no meio católico em seguida à conversão de largos estratos da população hindu, ainda que com importantes diferenças relativamente ao sistema original, seja em sua constituição ou em suas implicações sociais. É por meio sobretudo de histórias que se referem aos corriqueiros casamentos arranjados que essa literatura insiste em pintar a força das castas, não obstante abundarem referências a como elas estigmatizam ou estigmatizavam em Goa os mais variados tipos de relações sociais. A literatura indo-portuguesa não trata, porém, apenas disso, e findas malogradas tentativas literárias no século XIX em que se preteria Goa como fonte de inspiração para se investir na 
cópia de temas e motivos da literatura portuguesa, é a Goa colonial em toda a sua amplitude que virá a ocupar as produções locais. Estão lá a animosidade reprimida ou um discreto amor pelos paclé ("portugueses"), os contratempos e desenganos do entorno colonial e militar, a vida folgada e sobranceira das famílias da aristocracia rural (com uma singular atenção para com as "manas" solteironas e os histriônicos genros-comensais ${ }^{6}$ ), o carreirismo e a modorra no funcionalismo público, a difícil readaptação dos emigrados, a Índia "tradicional" ou hindu com a inevitável alta dose de idealização, a luta velada entre a língua portuguesa e os vernáculos, sem contar ainda a dura existência dos "subalternos" da Goa colonial e pós-colonial, de que o premiado e censurado romance $O$ signo da ira (1961) de Orlando da Costa constitui um dos melhores exemplos, ao retratar a vida dos curumbins, a casta cristã de trabalhadores rurais. Um outro importante exemplo desse aspecto são os contos de Epitácio Pais (1928-2010) em Os javalis de Codval (1973), que revelam um autor "extremamente preocupado com a vida à sua volta, e a febre do minério, que assaltou Goa (...) com a consequente deterioração do tipo tradicional de relações humanas” (SEABRA, 1973, p. 9). Há de se ressaltar ainda no temário indo-português, o constante embate entre as convicções modernas da elite educada do meio cristão e as crenças populares das camadas mais baixas de Goa, como o demonstra bem claramente o romance Bodki (1962) de Agostinho Fernandes (1932), em que um jovem médico da capital se vê confrontado às superstições da população de um vilarejo, em particular as que levam à marginalização da bodki, a viúva hindu, considerada responsável por todos os acontecimentos funestos que lá têm lugar.

\section{A evolução da literatura indo-portuguesa}

Nascida nos conventos católicos de Goa, a literatura indo-portuguesa se havia limitado, do século XVI ao século XVIII, a textos de caráter religioso e pedagógico ou preferindo abordar problemáticas ligadas às castas, para não

6. Numa casa onde só havia herdeiras após o falecimento dos pais, uma delas ficava responsável pela família e, quando se casava, o marido vinha habitar o lar, ganhando o estatuto de "genro-comensal".

7. No sentido gramsciano dos Subaltern Studies. 
dizer a justificação das mesmas, no seio de uma religião reputada orientar-se pelo princípio de igualdade fraterna. Foi apenas no século XIX, com a introdução em Goa do romantismo e do liberalismo, que começaram a surgir nessa literatura as primeiras obras de imaginação, nomeadamente no campo do romance, do conto e da poesia, onde os elementos temáticos referidos passaram, pouco a pouco, a ganhar droit de cité.

Curiosamente, o primeiro romance indo-português, sem se passar em Goa mesmo e quase não mencioná-la, constitui uma de suas mais poderosas representações, embora não invulgar, pois ainda hoje muitos veem a antiga Govapuri tal e qual. Trata-se do romance Os Brabamanes, publicado em Lisboa em 1866 por um deputado por Goa no Parlamento português, autor de trabalhos de caráter historiográfico e econômico, Francisco Luís Gomes (1829-1869). Tenho defendido que esse romance, a uma só vez de tese e exótico, poderia ser considerado não apenas como a primeira obra de ficção a atacar frontalmente o sistema de castas hindu, mas também a primeira de cunho anticolonialista na história da própria literatura moderna. É no tocante a este último ponto - ou na ambiguidade que ele encerra - que Goa surge. O romance de Francisco Luís Gomes faz, na verdade, uma crítica a um colonialismo desumano encarnado pelo regime inglês (a ação se desenrola na atual região do Uttar Pradesh, naquele momento então governada pelos britânicos) pela defesa de valores humanistas supostamente encarnados pela dimensão cristocêntrica da expansão portuguesa, ideia que desembocaria mais tarde no lusotropicalismo do brasileiro Gilberto Freyre e na propaganda salazarista em defesa das "províncias ultramarinas" de Portugal. Goa é mencionada diretamente no romance apenas duas vezes (numa, sem ser mesmo nomeada), mas o leitor atento dar-se-á conta - sendo Goa para o autor o exemplo confirmado da concretização daquele destino português - de que ela serve de contraponto à Índia britânica, à qual não são poupadas ferozes críticas.

A representação de Goa como repositório dos nobres ideais cristãos e portugueses pode ser encontrada, naturalmente, em autores posteriores, uns com mais, outros com menos distanciamento crítico. Ressalvadas as devidas proporções entre o período em que viveu Francisco Luís Gomes (marcado mais fortemente pelas armadilhas do mimetismo colonial) e o tempo de Orlando da Costa, ver-se-á que este não deixa de lembrar a todo momento em seu romance, como que a instigar as dúvidas existenciais da sua personagem 
Manú Miranda, o "desnorte" vivido por "povos forçados, um dia, a mudar de credo e altar" (COSTA, 2000, p. 175). No último romance, por ora, de língua portuguesa publicado por um goês, Casa Grande e outras recordações de um velho gôes (2008), de ninguém menos que o autor de um conhecido estudo sobre as confrarias religiosas de Goa, ${ }^{8}$ Leopoldo da Rocha (1932), chega-se a lamentar também a cristianização de Goa como um "desnorte" na vida dos naturais, mas em matéria de sexualidade. Leopoldo da Rocha, numa narrativa que se pretende autobiográfica, usa termos como "maniqueísmo" e "lavagem de cérebro" para definir a obra de cristianização em Goa, o primeiro tendo vindo a "contaminar a comunidade cristã de Goa, com as suas noções de pecado (sempre relacionadas com o sexo)", em contrapartida à "maneira natural" como o sexo era assumido entre os hindus (ROCHA, 2008, p. 45 e 79).

Essas observações do narrador de Casa Grande nos remetem para mais de cem anos atrás, o momento do "nativismo" nas letras goesas. A despeito da crença dos autores desse filão de estarem a realizar algo visceralmente indiano, é quase impossível para o leitor fazer abstração na leitura de suas obras do malfadado signo do exotismo e da educação religiosa que receberam. $\mathrm{Na}$ busca de utilizar costumes, mitos e lendas locais, a maior parte desses poetas, como Floriano Barreto (1877-1905), Eucaristino Mendonça (? -?), Mariano Gracias (1871-1931) e Paulino Dias (1874-1919), mostra-se completamente subjugada pelas bailadeiras dos templos hindus, ora recriminando-as, ora compadecendo-se de sua sorte, mas acabando sempre por sucumbir ao charme dessas figuras estigmatizadas da cultura hindu, o que levou Orlando da Costa a se perguntar um dia se a razão de as bailadeiras aparecerem "tão repetidamente como a musa inspiradora de tantos poetas cristãos" não estaria no fato de o “estigma [se ter] transformado em fonte de um imaginário erótico à revelia do casto puritanismo judaico-cristão de sexualidade reprimida e só raras vezes razão de crítica social" (COSTA, 1998, p. 12). A Goa que se entrevê nessa vaga nativista, ainda que não tenha sido esta a intenção de seus escritores, revela-se totalmente incompatível com a formação cristã e ocidental que receberam. De um modo geral, esses orientais ficaram confinados na utilização de inúmeros estereótipos recorrentes na Europa aplicados aos mesmos, cavando mais fundo o fosso entre as duas metades de uma mesma (?) identidade.

8. ROCHA, 1973. 
Se a poesia do período estava preocupada em ressaltar a parte nativa da identidade de seus escritores numa tentativa desesperada de corrigir os erros do passado da colonização portuguesa no obliterar completamente a cultura hindu, a prosa (conto e romance), ao dar os seus primeiros passos procurava focar-se na própria sociedade cristã resultante da simbiose entre os mundos ocidental e oriental de uma maneira tendenciosamente naturalista. A chave do que estaria por vir se encontra no romance que mais repercussão teve em Goa. Trata-se de Jacob e Dulce (1896) de Gip, pseudônimo de Francisco João da Costa, uma sátira da burguesia média da Goa católica e portuguesa, bastante servil à Europa, trazendo à luz tipos sociais que volta e meia serão dissecados também depois na literatura indo-portuguesa. Como lembra Joana Passos:

na narrativa de Gip, de capítulo para capítulo acompanhamos as negociações que levam ao casamento de Jacob e Dulce. Ilustram-se assim aspectos da vida social de Goa que são ridicularizados, sobretudo pelo que revelam de um padrão de superficialidade, de falta de educação e de projecto de vida, para além da muito criticada subserviência à cultura europeia (PASSOS, 2008, p. 50).

Gip teria até feito escola, tendo provavelmente inspirado os contos de José da Silva Coelho (1889-1944) que apareciam com regularidade nos jornais locais, sem poupar funcionários públicos e jovens casadoiras. Um Carmo de Noronha (1915-1999), já na contemporaneidade, herdeiro direto de Gip na crítica à dependência cultural, não causou menos dissabores em Goa ao descrever o goês do meio católico como um imitador barato. Fazendo, numa polêmica palestra de 1969 no Clube Vasco da Gama, o balanço do legado da colonização europeia após a mudança dos ventos na recém-iniciada era póscolonial, Carmo acusava a tão defendida "personalidade goesa" de

não passa[r] de uma manta de retalhos, em que somos europeus no traje, ingleses na língua, portugueses na moleza de hábitos e sentimentalismo, franceses na cozinha, italianos na música, medievais na religião, asiáticos na perfídia, astúcia e fatalismo e só goeses pelo registo civil (CARMO, 1991, p. 7).

Percepções da comunidade cristã de Goa como essa são indissociáveis das próprias escolhas literárias feitas pelos escritores indo-portugueses. Como havia observado Manuel de Seabra no prefácio aos contos de Epitácio Pais, 
sempre que quer assumir uma atitude trágica ou heroica, o escritor goês tem que abandonar a pequena burguesia (a que, de uma maneira geral, pertence) e se debruçar sobre as castas desprivilegiadas. Quando se vira para as classes médias, o escritor goês vê-se forçado a tomar uma de duas atitudes: ou levar as suas personagens a sério (como faz Alberto de Meneses Rodrigues e por vezes Maria Elsa da Rocha), arriscando-se a ser ele próprio ridículo; ou assumir uma atitude crítica, objectiva, alienante (SEABRA, 1973, p. 7).

Quando se aborda a comunidade hindu, a par da frequente exotização nas produções românticas e passadistas do período "nativista", os escritores, quando não assumem uma postura demasiado etnográfica ou mesmo francamente paternalista, esforçam-se em escapar aos essencialismos, de preferência na primeira atitude apontada por Manuel de Seabra.

\section{Considerações finais}

É por meio dessas maneiras de se encarar Goa que os escritores indo-portugueses acabaram por criar cada um para si uma "comunidade imaginada" (para usar a expressão de Benedict Anderson, 1983), sem que alguma delas tenha de fato chegado a constituir uma nação à parte da Índia e de Portugal, como muitos o teriam desejado, na esteira da propalada especificidade cultural goesa.

A expressão "comunidade imaginada" dever ser tomada aqui mais como uma metáfora para a maneira como Goa se inscreve no universo pessoal de cada escritor - e, naturalmente, de acordo não apenas com a sua formação intelectual mas também a sua condição social e o lugar da enunciação (boa parte deles lançou-se ainda jovem na aventura da diáspora goesa) -, sobretudo se levarmos em conta que o conceito de Benedict Anderson apresenta falhas quando aplicado a Goa, já que para ele o surgimento de uma nação correspondia ao processo moderno de secularização: na Goa portuguesa, pelo contrário, foi o processo de confessionalização, resultado da poderosa ação missionária europeia, que gerou diversas ideias, ao longo da história, de "comunidade" ou "nação". "

Uma delas é justamente a da imaginação de comunidade daqueles que "o póscolonialismo havia de encontrar mais afetados nos seus sentimentos de per-

9. Ver, a esse respeito, Xavier, 2008, p. 440. 
tença nacional e que recusavam as referências geográficas e civilizacionais indianas a favor da sua lusitanidade" (PEREZ, 2006, p. 142). A sua profunda ligação com o Ocidente não deixou de provocar - com a integração de Goa na União Indiana em 1961 - "enormes desequilíbrios na adaptação a uma nova nacionalidade, a uma nova língua, a um novo estatuto" (SARDO, 2011, p. 58).

No caso da literatura indo-portuguesa, e apesar dos mais representativos terem vindo a questionar a verdadeira dimensão dessa lusitanidade ou a tentar equacioná-la à luz do que seria por ventura a sua indianidade, os escritores parecem não ter conseguido resolver tais desequilíbrios, não só em função do dilaceramento provocado pela empresa colonial, mas ainda por dificilmente ser possível romper com os limites de uma cosmovisão (weltanschauung) que não é a mesma para hindus e católicos, e que a escolha da língua do colonizador como instrumento de trabalho veio condicionar ainda mais.

\section{Referências Bibliográficas}

ANDERSON, Benedict. Imagined Communities: Reflections on the Origin and Spread of Nationalism. Londres: Verso, 1983.

BARRETO, Adeodato. Civlização Hindu seguido de O Livro da Vida - Cânticos indianos. Lisboa: Hugin Editores, 2000.

COSTA, Orlando da. A literatura indo-portuguesa contemporânea: antecedentes e percurso. Colóquio Internacional Vasco da Gama e a Índia, Paris, maio de 1998, Fundação Calouste Gulbenkian (texto policopiado fornecido pelo autor).

. . Uma abordagem à literatura Indo-portuguesa contemporânea no roteiro da colonização. Aprender juntos. Maputo, n. 4-5, , jan. 2005.

COSTA, Orlando. O último olhar de Manú Miranda. Lisboa: Âncora, 2000.

DEVI, Vimala. Súria. Lisboa: Agência-Geral do Ultramar, 1962.

MIRANDA, Eufemiano de Jesus. Literatura indo-portuguesa dos séculos XIX e XX: um estudo de temas principais no contexto sócio-histórico. Apresentada como tese de doutorado em Letras, Universidade de Goa, 1995.

NORONHA, Carmo de. A libertação psíquica em Goa. In: Contracorrente. Pangim: edição do autor, 1991.

PASSOS, Joana. A ambivalência de Goa como imagem do império português e as representações da sociedade colonial na literatura luso-indiana. e-cadernos ces, n. 1, 2008. Disponível em: <www.ces.uc.pt/e-cadernos>. Acesso em: 20 ago. 2010. 
PEREZ, Rosa Maria. Sonhos imperiais. Negociações e rupturas do colonialismo português na Índia. In: PEREZ, Rosa Maria (Coord.). Os Portugueses e o Oriente - História, itinerários, representações. Lisboa: Dom Quixote, 2006.

ROCHA, Leopoldo da. As confrarias de Goa: conspecto histórico-jurídico. Lisboa: Centro de Estudos Históricos Ultramarinos, 1973. . Casa Grande e outras recordações de um velho gôes. Lisboa: Vega, 2008.

SANSKRIT Heritage Dictionary. Disponível em: <http://sanskrit.inria.fr/sanskrit. html>. Acesso em: 19 ago. 2010.

SARDO, Susana. Guerras de Jasmim e Mogarim - Música, Identidade e Emoções em Goa. Lisboa: Texto, 2011.

SEABRA, Manuel de. Prefácio. PAIS, Epitácio. Os Javalis de Codval. Lisboa: Futura, 1973.

XAVIER, Ângela Barreto. A Invenção de Goa-Poder imperial e conversões culturais nos séculos XVT е XVII. Lisboa: ICS, 2008.

Recebido em 16/02/2011 e aprovado em 26/03/2011. 